\section{Pulmonary Abnormalities in Patients with Early and Longstanding Rheumatoid Arthritis}

\section{To the Editor:}

We read with interest the article by Mori, et al regarding the pulmonary abnormalities in patients with early and longstanding rheumatoid arthritis $(\mathrm{RA})^{1}$. We would like to add some new data on this subject. The authors reported no significant differences on imaging abnormalities in the lung between patients with early and longstanding RA. The question arises, how do the authors explain these findings? The prevalence and the severity of lung involvement in patients with RA are related to disease severity, to extraarticular manifestations, to extent of joint and bone damage, and to disease duration ${ }^{2,3}$. None of these measures are examined and discussed appropriately by the authors. Other factors that may influence lung involvement in patients with RA are smoking and the use of disease modifying antirheumatic drugs (DMARD) ${ }^{4-6}$. Although the investigators excluded patients treated with methotrexate (MTX) and with anticytokine agents, another question is what kind of DMARD did they use to treat their patients, because gold salts, D-penicillamine, and others may cause lung abnormalities $^{4-6}$. The third point is that no control group was included in their study (healthy nonsmokers). Our group investigated the pulmonary abnormalities in patients with early RA using high resolution computed tomography $(\mathrm{HRCT})^{7}$. For this reason 43 patients with early RA were included. All patients had disease duration $<1$ year without prior use of DMARD or steroids. Disease activity was assessed using the 28 -joint Disease Activity Score (DAS-28). Hand and wrist radiographs were evaluated using Larsen's criteria. In addition, plain chest radiographs were performed in all patients, while pulmonary function tests (PFT) were evaluated in 32 patients. Finally, 18 healthy nonsmoking volunteers were used as a control group. HRCT revealed air-trapping in 69\%, bronchiectasis in $58 \%$, bronchial wall thickening in $52 \%$, and ground-glass opacities in $35 \%$ of the patients. Chest radiograph was abnormal in 1 patient, revealing a single pulmonary nodule. However, from all these abnormalities, groundglass opacities were seen exclusively in early RA. All the other abnormalities were found in the control group at the same frequency as in the patients. DAS-28, PFT, and the Larsen score showed no significant correlations with either each HRCT sign score separately or the total score ${ }^{7}$.

We feel that the data presented by Mori, et al should be interpreted cautiously. It seems that pulmonary involvement is frequent in patients with
RA, but many factors may influence it, such as smoking, the use of DMARD, longstanding disease, and others. Thus, to investigate whether pulmonary abnormalities in patients with RA are related to disease activity itself, a prospective, well controlled longitudinal study is required, which is now in progress by our group.

ATHANASIOS N. GEORGIADIS, MD, Rheumatology Clinic, Department of Internal Medicine; ZAFIRIA M. METAFRATZI, MD, Registrar of Radiology, Department of Clinical Radiology and Imaging, Medical School; ALEXANDROS A. DROSOS, MD, FACR, Professor of Medicine/Rheumatology, Head, Rheumatology Clinic, Department of Internal Medicine, Medical School, University of Ioannina, 45110 Ioannina, Greece. Address reprint requests to Prof. Drosos.

E-mail: adrosos@cc.uoi.gr

\section{REFERENCES}

1. Mori S, Cho I, Koga Y, Sugimoto M. Comparison of pulmonary abnormalities on high-resolution computed tomography in patients with early versus longstanding rheumatoid arthritis. J Rheumatol 2008;35:1513-21.

2. Anaya JM, Diethelm L, Ortiz LA, et al. Pulmonary involvement in rheumatoid arthritis. Semin Arthritis Rheum 1995;24:242-54.

3. Turesson C, O'Fallon WM, Crowson CS, Gabriel SE, Matteson EL. Extra-articular disease manifestations in rheumatoid arthritis: incidence trends and risk factors over 46 years. Ann Rheum Dis 2003;62:722-7.

4. McFadden RG, Fraher LJ, Thompson JM. Gold-naproxen pneumonitis. A toxic drug interaction? Chest 1989;96:216-8.

5. Tomioka R, King TE Jr. Gold-induced pulmonary disease: clinical features, outcome, and differentiation from rheumatoid lung disease. Am J Respir Crit Care Med 1997;155:1011-20.

6. Camus P, Degat OR, Justrabo E, Jeannin L. D-penicillamine-induced severe pneumonitis. Chest 1982;81:376-8.

7. Metafratzi ZM, Georgiadis AN, Ioannidou CV, et al. Pulmonary involvement in patients with early rheumatoid arthritis. Scand J Rheumatol 2007;36:338-44.

J Rheumatol 2009;36:2; doi:10.3899/jrheum.080882 